\title{
Examination of the Rumen Bacteria and Methanogenic Archaea of Wild Impalas (Aepyceros melampus melampus) from Pongola, South Africa
}

\author{
Laura M. Cersosimo, Hannah Lachance, Benoit St-Pierre, Wouter van Hoven, André-Denis G. Wright
}

\begin{abstract}
Although the rumen microbiome of domesticated ruminants has been evaluated, few studies have explored the rumen microbiome of wild ruminants, and no studies have identified the rumen microbiome in the impala (Aepyceros melampus melampus). In the present study, next-generation sequencing and real-time polymerase chain reaction were used to investigate the diversity and density of the bacteria and methanogenic archaea residing in the rumen of five adult male impalas, culled during the winter dry season in Pongola, South Africa. A total of 15,323 bacterial 16S rRNA gene sequences (from five impala), representing 3,892 different phylotypes, were assigned to 1,902 operational taxonomic units (OTUs). A total of 20,124 methanogen 16S rRNA gene sequence reads (from four impala), of which 5,028 were unique, were assigned to 344 OTUs. From the total sequence reads, Bacteroidetes, Proteobacteria, and Firmicutes were the most abundant bacterial phyla. While the majority of the bacterial genera found were unclassified, Prevotella and Cupriavidus were the most abundant classified genera. For methanogens, the genera Methanobrevibacter and Methanosphaera represented $94.3 \%$ and $4.0 \%$ of the classified sequences, respectively. Most notable was the identification of Methanobrevibacter thaueri-like 16S rRNA gene sequence reads in all four impala samples, representing greater
\end{abstract}

L. M. Cersosimo • H. Lachance • B. St-Pierre • A.-D. G. Wright Department of Animal Science, The University of Vermont, 570 Main Street, Burlington, VT 05405, USA

W. van Hoven

Center for Wildlife Management, University of Pretoria, Pretoria, South Africa

Present Address:

A.-D. G. Wright ( )

School of Animal and Comparative Biomedical Sciences, The University of Arizona, 1117 E. Lowell, Tucson, AZ 85721, USA

e-mail: adwright@email.arizona.edu than $30 \%$ of each individual's total sequences. Both data sets are accessible through NCBI's Sequence Read Archive (SRA), under study accession number SRP [048619]. The densities of bacteria $\left(1.26 \times 10^{10}-3.82 \times 10^{10}\right.$ cells $/ \mathrm{ml}$ whole rumen contents) and methanogens $\left(4.48 \times 10^{8}-7.2 \times 10^{9}\right.$ cells $/ \mathrm{ml}$ of whole rumen contents) from five individual impala were similar to those typically observed in domesticated ruminants.

Keywords Archaea $\cdot$ Bacteria $\cdot$ Methanogen $\cdot$ Impala . Rumen · Wild ruminant

\section{Introduction}

Impala belong to the subfamily Aepycerotinae within the family Bovidae, the latter also including other ruminants such as, cattle, antelopes, gazelles, goats, and sheep [1]. It is hypothesized that members of the subfamily Aepycerotinae diverged from their Caprine relatives some 6.5 million years ago [2]. Impalas are native to and widely distributed throughout sub-Saharan Africa and are further divided into two subspecies, the common impala, Aepyceros melampus melampus, which typically inhabits the northern parts of the KwaZuluNatal region of South Africa and Kenya, and the less common, black-faced impala, Aepyceros melampus petersi, which inhabits Angola and Namibia [3,4]. As a result of human encroachment and hunting for both prize and food, impala have been removed from a substantial part of their original range and are more abundant in protected areas within South Africa $[3,5,6]$.

Impalas, like all ruminants, have a consortium of diverse microorganisms that reside in the rumen. During the normal process of fermentation of feed, hydrogen is released from bacteria, protozoa, and fungi, and through interspecies hydrogen transfer, methane-producing Archaea, called 
methanogens, utilize hydrogen $[7,8]$. The majority of the methane produced, called enteric methane, is eructated or exhaled by the host, resulting in the accumulation of greenhouse gases trapped within the atmosphere, thereby contributing to global warming.

Limited studies have explored the microorganisms within the foregut of wild ruminants, and no studies have investigated the bacterial and archaeal diversities and densities within the impala rumen. Previous studies that observed the microbiome of wild ruminants included the Svalbard reindeer (Rangifer tarandus platyrhynchus), moose (Alces alces), yak (Bos grunniens), elk (Cervus canadensis), white-tailed deer (Odocoileus virginianus), and the semi-domesticated Norwegian reindeer (Rangifer tarandus tarandus) [9-13]. The exploration of the rumen microbiota in wild animals, such as the impala, aims to improve our understanding of their rumen microorganisms in comparison to their domesticated relatives. Because impalas are mixed adaptable feeders with diets of intermediate quality, it was hypothesized that the diversity and density of the rumen bacteria and archaea would be significantly different from those of domesticated ruminants, in order for the animals to adapt to extreme seasonal fluctuations in diet. The objectives of the present study were to (1) determine the bacterial and methanogen densities of each individual impala; (2) identify the bacterial and methanogen taxa within the rumen of the impala; and (3) to compare and contrast the diversity and density of the impala microbiota to those of previously studied domesticated and wild ruminants.

\section{Methods and Materials}

\section{Animal Sampling}

During the June 2011 winter dry season, $10 \mathrm{ml}$ of whole rumen contents were immediately collected by hunters from five legally hunted, adult, male impalas from the province of Kwazulu-Natal of the Pongola, South Africa district. The University of Vermont's Institutional Biosafety Committee approved all relevant laboratory procedures under protocol number 10-029. Prior to their arrival at the University of Vermont in October 2011, the samples were immediately fixed in $95 \%$ ethanol at room temperature. The five homogenized samples were immediately transferred from Vacutainers to $15-\mathrm{ml}$ tubes and spun down in a refrigerated Eppendorf centrifuge at $5,795 \times g$ for $10 \mathrm{~min}$ at $6{ }^{\circ} \mathrm{C}$. The liquid fraction was decanted, and the pellet retained in the 15-ml tube for DNA extraction.

\section{DNA Extraction}

Microbial DNA was extracted using the repeated bead-beating plus column $(\mathrm{RBB}+\mathrm{C})$ method described by $\mathrm{Yu}$ and Morrison
[14] but excluded the DNase-free RNase step. Additionally, half of an InhibitEX tablet was dissolved in each pooled supernatant per animal for the absorption of polymerase chain reaction (PCR) inhibitors (QIAGEN, Germantown, MD). After the extraction, the DNA samples were stored at $-20{ }^{\circ} \mathrm{C}$.

\section{Real-Time PCR Amplification}

Each real-time PCR used $12.5 \mu \mathrm{l}$ of $\mathrm{SYBR}^{\circledR}$ Green Mix, $6.5 \mu \mathrm{l}$ of double distilled water, and $1 \mu \mathrm{l}$ of diluted template DNA $(10 \mathrm{ng} / \mu \mathrm{l})$ with either the bacterial primer pair, 1114-F and 1275-R [15] for the 16S rRNA gene, or the methanogen primer pair, mcrA-F and mcrA-R $(2.5 \mu \mathrm{l}$ /reaction) for the alpha subunit of the methyl-coenzyme $\mathrm{M}$ reductase gene [16]. Each real-time PCR amplification was performed in a BioRad C1000 Touch Thermal Cycler (Bio-Rad, Hercules, CA). Both the bacteria and methanogens were amplified under the following conditions: hot start $\left(95^{\circ} \mathrm{C}, 15 \mathrm{~s}\right)$, followed by 40 cycles of $95^{\circ} \mathrm{C}$ for $30 \mathrm{~s}, 60^{\circ} \mathrm{C}$ for $30 \mathrm{~s}$, and $72{ }^{\circ} \mathrm{C}$ for $30 \mathrm{~s}$ with a final melting curve analysis of the fluorescence was performed between $60^{\circ} \mathrm{C}$ and $95^{\circ} \mathrm{C}$ with increments of $0.5^{\circ} \mathrm{C}$ every $10 \mathrm{~s}$. Microbial densities were determined following established protocols [9].

\section{PCR Amplification and Gel Extraction}

The methanogen primer pair, Met86F [16] and Met471R (5'-GWRTTACCGCGGCKGCTG-3'), and the bacteriaspecific primer pair, $27 \mathrm{~F}$ [17] and 519R [18], were used to PCR-amplify the V1-V3 hypervariable regions of the 16S rRNA gene on a BioRad C1000 Thermal Cycler. Both bacterial and methanogen PCR amplifications were performed with Thermo Scientific Phusion DNA polymerase. Using $2 \mu \mathrm{l}$ of extracted DNA (diluted to $10 \mathrm{ng} / \mu \mathrm{l}$ ), the bacteria were amplified in a $50 \mu 1$ volume under the following conditions: a hot start $\left(98^{\circ} \mathrm{C}, 4 \mathrm{~min}\right)$, followed by 35 cycles of denaturation $\left(98^{\circ} \mathrm{C}, 10 \mathrm{~s}\right)$, annealing $\left(50^{\circ} \mathrm{C}\right.$, $30 \mathrm{~s})$, extension $\left(72^{\circ} \mathrm{C}, 30 \mathrm{~s}\right)$, and a 6 -min extension in the final cycle. For methanogens, $5 \mu \mathrm{l}$ of extracted DNA was used in a $50 \mu \mathrm{l}$ volume under the following conditions: a hot start $\left(95^{\circ} \mathrm{C}, 2.5 \mathrm{~min}\right)$ followed by 40 cycles of denaturation $\left(95^{\circ} \mathrm{C}, 30 \mathrm{~s}\right)$, annealing $\left(50^{\circ} \mathrm{C}, 30 \mathrm{~s}\right)$, and extension $\left(72{ }^{\circ} \mathrm{C}, 30 \mathrm{~s}\right)$ with a $4 \mathrm{~min}$ extension at $72{ }^{\circ} \mathrm{C}$ in the final cycle.

All PCR products were excised from the gel and cleaned using the QIAquick Gel Extraction Kit according to the manufacturer's protocol (Qiagen, Germantown, MD). Each sample was eluted on a column with $30 \mu$ of Qiagen's EB buffer. Purified samples were sent to Molecular Research DNA Laboratories in Shallowater, TX, for Roche 454-pyrosequencing. 
Bioinformatics Analysis of Pyrosequences

MOTHUR ver.1.32.1 was used to analyze the bacterial and methanogen sequence reads. The "trim.seqs" command removed the PCR primers and barcodes from the sequences and removed any sequences $<350$ and $>400$ base pairs (bp). The "shhh.flows" command employed the PyroNoise algorithm to denoise the sequences from the standard flowgram format (sff) output file [19, 20]. A Needleman-Wunsch pairwise alignment method with a custom template was performed on the sequences using "align.seqs." Both Chimera-slayer and UCHIME commands detected chimeric sequences, and "remove.seqs" eliminated the chimeras from the data sets. The command "dist.seqs" was used on the aligned bacterial and methanogen sequences to determine genetic distances at 3 and $5 \%$, respectively. The cluster command grouped the methanogen and bacterial unique sequences into operational taxonomic units (OTUs).

Using the Ribosomal Database Project (RDP) Classifier at an $80 \%$ confidence threshold, bacterial sequences were classified to phyla, while methanogen sequences were classified down to the genus-level. Because RDP Classifier could not give bacterial sequence identities beyond taxonomic class, the SILVA reference taxonomy was used with an $80 \%$ cutoff to classify individual impala bacterial sequence reads to taxonomic genera. For individual methanogen analyses, the representative sequence reads from the most abundant OTUs 1-8 (i.e., at least one sample with an OTU representative $>1 \%$ ) were entered into GenBank's Nucleotide Basic Local Alignment Search Tool (nBLAST) [21], and the nearest valid species was identified along with the percent sequence similarity.

\section{Results}

Both data sets are accessible through NCBI's SRA, under study accession number SRP [048619].

\section{Real-Time PCR Amplification Analysis}

Densities of rumen methanogens ranged from $4.48 \times 10^{8}-7.2 \times$ $10^{9}$ cells $/ \mathrm{ml}$ of whole rumen contents, whereas rumen bacterial densities ranged from $1.26 \times 10^{10}-3.82 \times 10^{10}$ cells $/ \mathrm{ml}$ of whole rumen contents (Table 1).

\section{Analysis of Rumen Bacteria}

A total of 15,323 sequence reads were generated from five impala samples. From the total sequence reads, 3,892 were unique and trimmed to $376 \mathrm{bp}$ in length. The total sequence reads per sample were: Impala-1 $(4,913)$, Impala-2 $(3,862)$,
Table 1 Bacteria and methanogen densities from real-time PCR amplification $\left(R^{2}=0.997\right)$ and statistical analysis of whole rumen contents from individual impala

\begin{tabular}{lllll}
\hline Microorganism & Animal & $\begin{array}{l}\text { Microbial } \\
\text { density } \\
\text { (cells/ml) }\end{array}$ & $\begin{array}{l}\text { Good's } \\
\text { coverage } \\
(\%)\end{array}$ & $\begin{array}{l}\text { Shannon- } \\
\text { Weaver } \\
\text { Index }\end{array}$ \\
\hline Bacteria & & & & \\
& Impala 1 & $3.10 \times 10^{10}$ & 59.6 & $5.79 \pm 0.080$ \\
& Impala 2 & $1.25 \times 10^{10}$ & 49.2 & $5.80 \pm 0.930$ \\
& Impala 3 & $3.82 \times 10^{10}$ & 48.4 & $5.42 \pm 0.120$ \\
& Impala 4 & $1.52 \times 10^{10}$ & 46.2 & $5.66 \pm 0.096$ \\
& Impala 5 & $3.15 \times 10^{10}$ & 45.5 & $5.66 \pm 0.097$ \\
& Mean (SE) & $2.57 \times 10^{10}$ & $\left(5.00 \times 10^{9}\right)$ & \\
& & & & \\
& Impala 1 & $4.46 \times 10^{9}$ & 99.8 & $2.18 \pm 0.500$ \\
& Impala 2 & $4.95 \times 10^{8}$ & $\mathrm{~N} / \mathrm{A}$ & $\mathrm{N} / \mathrm{A}$ \\
& Impala 3 & $7.20 \times 10^{9}$ & 99.6 & $1.98 \pm 0.060$ \\
& Impala 4 & $4.48 \times 10^{8}$ & 99.6 & $1.28 \pm 0.050$ \\
& Impala 5 & $1.42 \times 10^{9}$ & 99.7 & $1.18 \pm 0.040$ \\
& Mean (SE) & $2.81 \times 10^{9}$ & $\left(1.32 \times 10^{9}\right)$ &
\end{tabular}

Impala-3 (1,986), Impala-4 $(2,160)$, and Impala-5 $(2,402)$. The 3,892 unique sequence reads were assigned to 1,902 OTUs. The unique sequence reads per animal were assigned to variable OTUs and a range of Shannon-Weaver indices and Good's coverages [22, 23] (Table 1). The OTU representatives that were greater than $1 \%$ of the total sequence reads per individual, number of OTUs per sample, and the percent identities are displayed in Table 2. The most abundant individual impala OTU representatives varied from sample to sample, with the top OTUs representing between 5.1 and $10.2 \%$ of the total unique sequence reads per individual.

From the unique sequences, the most dominant group was unclassified (34.4\%), followed by the phyla Firmicutes (32.1\%), Bacteroidetes (23.1\%), Proteobacteria (8.3\%), and Actinobacteria (1.4\%). The phyla Lentisphaerae, Fibrobacteres, and Spirochaetes represented less than $1 \%$ of the unique sequences. In comparison, the Silva taxonomy file showed that $27.5 \%$ of the total sequence reads were unclassified (Fig. 1). Notably, Impala 3 had the most unclassified phyla at $48.6 \%$, while Impala 1 had the lowest at $17.0 \%$. Across all five impala, the phyla Bacteroidetes (26.9\%), Proteobacteria (23.5\%), and Firmicutes $(20.9 \%)$ were the most abundant phyla, comprising $71.3 \%$ of the total sequence reads. On an individual basis, Impalas 1, 4, and 5 had more sequences belonging to the phylum Bacteroidetes than Impalas 2 and 3, which had more sequences belonging to the phylum Firmicutes. Lastly, more sequence reads were identified from the phylum Proteobacteria in Impalas $1(24.3 \%), 2$ $(42.0 \%)$, and $5(23.0 \%)$ than in Impalas $3(5.24 \%)$ and 4 $(5.65 \%)$. 
Table 2 Distribution of the most abundant ( $>1 \%$ ) rumen bacterial OTUs among individual impala

\begin{tabular}{|c|c|c|c|c|c|}
\hline $\begin{array}{l}\text { Animal } \\
\text { (total } \\
\text { OTUs) }\end{array}$ & out & $\begin{array}{l}\text { No. of } \\
\text { unique } \\
\text { sequences }\end{array}$ & $\begin{array}{l}\% \text { of unique } \\
\text { sequences }\end{array}$ & $\begin{array}{l}\% \\
\text { Identity }\end{array}$ & Related taxa \\
\hline \multirow[t]{2}{*}{ Impala 1} & 1 & 62 & 5.1 & 94 & Cupriavidus \\
\hline & 3 & 40 & 3.3 & 98 & Lachnospiraceae \\
\hline \multirow[t]{9}{*}{$(628)$} & 8 & 32 & 2.6 & 100 & Prevotellaceae \\
\hline & 11 & 27 & 2.2 & 100 & Prevotella \\
\hline & 9 & 23 & 1.9 & 100 & Prevotella \\
\hline & 13 & 23 & 1.9 & 96 & Prevotella \\
\hline & 6 & 21 & 1.7 & 100 & Lachnospiraceae \\
\hline & 16 & 21 & 1.7 & 100 & Prevotella \\
\hline & 10 & 20 & 1.6 & 100 & Unclassified bacteria \\
\hline & 4 & 15 & 1.2 & 100 & Rikenellaceae \\
\hline & 19 & 15 & 1.2 & 100 & Prevotella \\
\hline \multirow[t]{2}{*}{ Impala 2} & 1 & 55 & 6.7 & 95 & Cupriavidus \\
\hline & 2 & 25 & 3.1 & 100 & Unclassified bacteria \\
\hline \multirow[t]{5}{*}{ (519) } & 6 & 19 & 2.3 & 95 & Butyrivibrio \\
\hline & 3 & 12 & 1.5 & 100 & Lachnospiraceae \\
\hline & 18 & 11 & 1.3 & 100 & Unclassified bacteria \\
\hline & 4 & 10 & 1.2 & 100 & Rikenellaceae \\
\hline & 7 & 10 & 1.2 & 100 & Unclassified bacteria \\
\hline \multirow[t]{2}{*}{ Impala 3} & 2 & 59 & 10.2 & 100 & Unclassified bacteria \\
\hline & 3 & 15 & 2.6 & 100 & Lachnospiraceae \\
\hline \multirow[t]{4}{*}{ (369) } & 7 & 13 & 2.2 & 100 & Unclassified bacteria \\
\hline & 14 & 13 & 2.2 & 100 & Clostridiales \\
\hline & 4 & 7 & 1.2 & 100 & Rikenellaceae \\
\hline & 15 & 7 & 1.2 & 100 & Lachnospiraceae \\
\hline \multirow[t]{2}{*}{ Impala 4} & 5 & 35 & 5.6 & 92 & Prevotella \\
\hline & 4 & 20 & 3.1 & 100 & Rikenellaceae \\
\hline \multirow[t]{3}{*}{ (414) } & 2 & 19 & 3.0 & 100 & Unclassified bacteria \\
\hline & 8 & 9 & 1.4 & 100 & Prevotella \\
\hline & 7 & 5 & 1.3 & 100 & Unclassified bacteria \\
\hline \multirow[t]{2}{*}{ Impala 5} & 2 & 33 & 5.1 & 100 & Unclassified bacteria \\
\hline & 1 & 22 & 3.4 & 100 & Cupriavidus \\
\hline \multirow[t]{6}{*}{ (428) } & 7 & 20 & 3.1 & 100 & Unclassified bacteria \\
\hline & 4 & 12 & 1.9 & 100 & Rikenellaceae \\
\hline & 5 & 12 & 1.9 & 100 & Prevotella \\
\hline & 48 & 8 & 1.2 & 100 & Prevotella \\
\hline & 3 & 7 & 1.1 & 100 & Lachnospiraceae \\
\hline & 44 & 7 & 1.1 & 100 & Lachnospiraceae \\
\hline
\end{tabular}

Classification of total sequence reads to the genus level showed unclassified bacteria were the most abundant group, between 48.6 and $85.8 \%$ of the total sequence reads per individual (Fig. 2). The top three classified genera were Prevotella, Cupriavidus, and Butyrivibrio. The genus Prevotella was the most abundant genus from Impalas 1 $(23.4 \%)$ and 4 (31.3\%). However, Cupriavidus was the most abundant genus from Impalas $2(34.9 \%)$ and 5
(16.9\%). In contrast, Impala 3 had the highest percentage of unclassified genera $(85.8 \%)$ with Butyrivibrio $(4.38 \%)$ as the most abundant classified genus. The following 34 genera were also identified from the impala rumen, but at a very low prevalence (i.e., $<5 \%$ of each individual's total sequence reads): Acetitomaculum, Achromobacter, Acinetobacter, Anaerobiospirillum, Anaerospora, Aquabacterium, Aquincola, Atopobium, Bradyrhizobium, ButyrivibrioPseudobutyrivibrio, Campylobacter, Coprococcus, Coriobacterium, Desulfovibrio, Gordonia, Howardella, Methylobacterium, Mitsuokella, Mogibacterium, Olsenella, Oscillibacter, Oscillospira, Rhizobium, Ruminococcus, Schwartzia, Selenomonas, Slackia, Solobacterium, Sphingomonas, Streptococcus, Succiniclasticum, Syntrophococcus, Variovorax, and Victivallis.

\section{Analysis of Rumen Methanogens}

A total of 26,771 sequence reads were obtained from four impala. Note that useable sequences were not obtained from Impala 2. After denoising and chimera checking, 20,124 sequences, representing 5,028 unique phylotypes, trimmed to $358 \mathrm{bp}$ in length, were assigned to 344 OTUs. The total sequence reads per individual were: Impala $1(6,902)$, Impala 3 $(4,147)$, Impala $4(2,927)$, and Impala $5(6,148)$. All individual samples had Good's coverages greater than $99 \%$ and had similar Shannon indices (Table 1).

Three unique sequences could not be classified using RDP Classifier, whereas all remaining sequences belonged to the phylum Euryarchaeota. Of these 5,025 unique sequences, 4,718 sequences $(93.9 \%)$ were classified to the genus Methanobrevibacter; 213 sequences $(4.2 \%)$ belonged to the genus Methanosphaera; 78 sequences $(1.6 \%)$ were unclassified at the genus level within the family Methanobacteriaceae, and 16 sequences $(0.3 \%)$ were unclassified Euryarchaeota.

Both the combined and individual sequence reads from the eight most abundant OTUs along with the percent sequence identities are presented in Table 3. Overall, the eight most abundant OTUs accounted for $88.1 \%$ of the 20,124 sequence reads, while the remaining 2,395 (11.9\%) sequences were assigned to 336 OTUs. OTU 1, with $98.3 \%$ species-level identity to $M$. thaueri, accounted for the majority of the total sequences for Impalas 1, 4, and 5. Whereas OTU 2, with $98.6 \%$ species-level identity to Methanobrevibacter smithii, accounted for the majority of the sequence reads in Impala-3. From the most abundant OTUs, OTUs 1-6 and 8 were shared among all five impala. However, Impala-3 was the only individual with no sequence reads in OTU 7 (Table 3). Furthermore, the Methanobrevibacter smithiigottschalkii-millerae-thaueri (SGMT) clade composed $81 \%$ of the sequence reads from OTUs $1-8$ while the Methanobrevibacter ruminantium-olleyae (RO) clade accounted for just $2 \%$ [24]. 
Fig. 1 Silva taxonomy classification of bacterial 16S rRNA sequence reads $(15,323)$ to phylum level from whole rumen contents from individual impala

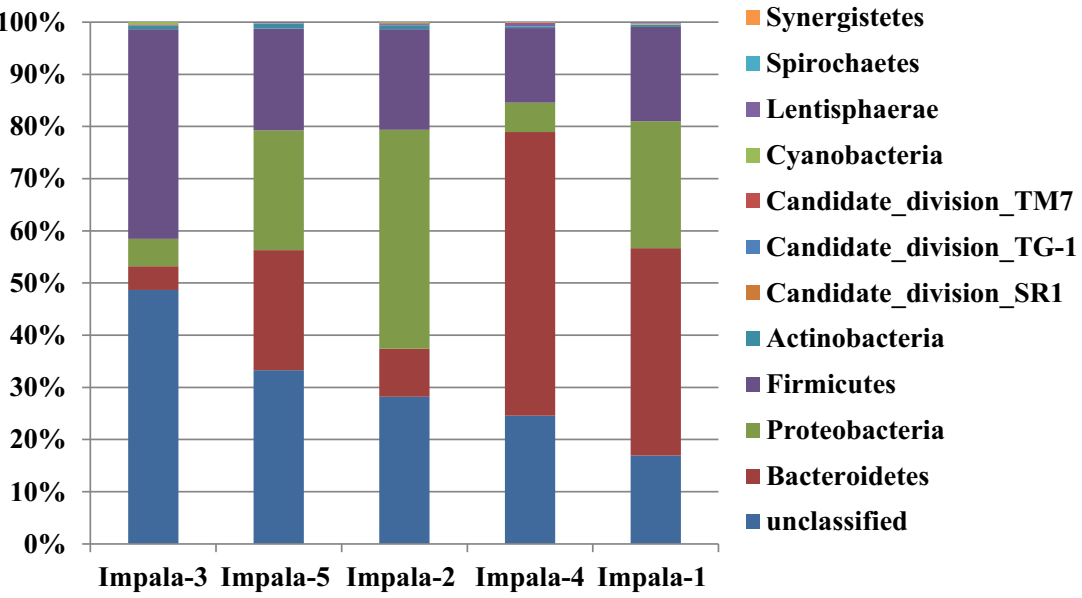

\section{Discussion}

Impala Rumen Methanogen and Bacterial Densities

In contrast to our hypothesis, the estimated five impala rumen bacterial and five methanogen densities were similar to those previously studied in Norwegian reindeer on summer pasture and with a different primer pair [9]. Methanogen densities also agreed with those observed in Swedish dairy cattle, alpaca, and Brahman-cross cattle [16, 25, 26]. However, lower methanogen densities were observed in buffalo, Atlay sheep, and Svalbard reindeer [10, 26, 27]. Further studies are needed to determine if the higher impala methanogen densities coincide with seasonal dietary changes or if they are a true reflection of differences in the rumen microbiome.

Impala Rumen Bacterial Taxa in Relation to Domestic and Wild Ruminants

Unclassified bacteria at the phylum level represented the majority of the unique and total impala sequence reads.
Previous studies involving Jinnan cattle from China, elk, and white tailed deer from Canada, Moxotó goats from Brazil, water buffalo from India, and moose throughout North America had unclassified bacteria in the rumen but at lower prevalence than the impala [13, 28-31]. The prevalence of unclassified bacteria in the rumen may be a reflection of the impala's diverse diet of both browse and graze and speculated to be a result of a dry, winter diet, consisting of leaves, pods, twigs, dried grasses, and bushvelds [4, 32].

Prior to this study, it was determined that the phyla Firmicutes, Bacteroidetes, and Proteobacteria were the most abundant rumen sequences in GenBank [33]. Similarly, the same three phyla were the most abundant sequence reads from impala. The dominance of the phylum Bacteroidetes was in agreement with previous research involving moose from Alaska and Norway, Sika deer, water buffalo, Svalbard reindeer consuming a winter diet, and mithun consuming mixed tree leaves and rice straw [10, 29, 30, 33, 34]. It has been suggested that plant starches are associated with the phylum Bacteroidetes and structural carbohydrates (e.g., cellulose, hemicellulose, and lignin) are associated with the phylum
Fig. 2 Silva taxonomy classification of bacterial $16 \mathrm{~S}$ rRNA sequence reads $(15,323)$ to genus level from whole rumen contents from individual impala

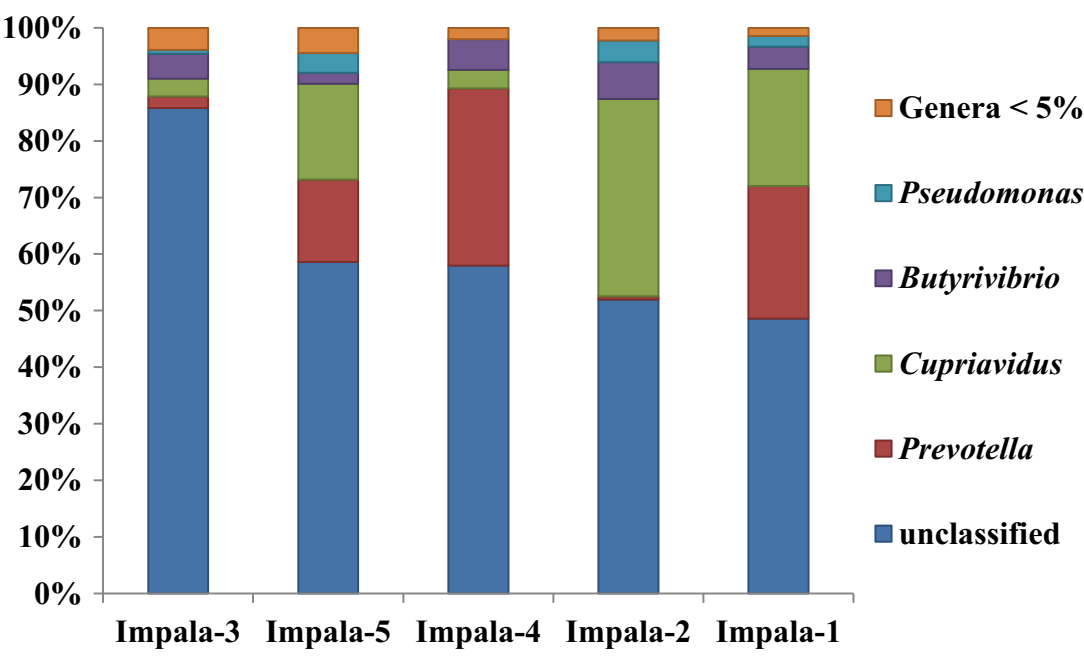


Table 3 Individual taxonomic representations of rumen methanogen 16S rRNA gene sequence reads from OTUs 1-8

\begin{tabular}{|c|c|c|c|c|c|c|c|}
\hline \multirow[t]{2}{*}{ OTU } & \multicolumn{5}{|c|}{ Number of sequence reads ( $\%$ of total sequences) } & \multirow[t]{2}{*}{ Nearest valid species } & \multirow[t]{2}{*}{$\%$ Sequence identity } \\
\hline & Impala 1 & Impala 3 & Impala 4 & Impala 5 & Total & & \\
\hline 1 & $2,734(39.6)$ & $885(30.2)$ & $4,488(73.0)$ & $2,216(53.4)$ & $10,323(51.3)$ & M. thaueri & 98.3 \\
\hline 2 & $2,338(28.0)$ & $1,623(55.4)$ & $839(13.6)$ & $576(13.9)$ & $5,376(26.7)$ & Methanobrevibacter smithii & 98.6 \\
\hline 3 & $61(0.88)$ & $4(0.1)$ & $186(3.0)$ & $312(7.5)$ & $563(2.8)$ & Msp. gottschalkii & 97.8 \\
\hline 4 & $44(0.6)$ & $13(0.4)$ & $143(2.3)$ & $320(7.7)$ & $520(2.6)$ & Methanobrevibacter ruminantium & 97.2 \\
\hline 5 & $151(2.2)$ & $109(3.7)$ & $17(0.3)$ & $23(0.6)$ & $300(1.5)$ & Msp. stadtmanae & 95.6 \\
\hline 6 & $86(1.2)$ & $31(1.1)$ & $14(0.2)$ & $109(2.6)$ & $240(1.2)$ & Methanobrevibacter smithii & 96.9 \\
\hline 7 & $163(2.4)$ & $0(0.0)$ & $60(1.0)$ & $7(0.2)$ & $230(1.1)$ & Msp. stadtmanae & 95.0 \\
\hline 8 & $7(0.1)$ & $144(1.1)$ & $20(0.3)$ & $12(0.3)$ & $183(0.9)$ & Msp. stadtmanae & 94.8 \\
\hline Total seq OTUs $1-8$ & $5,584(80.9)$ & $2,809(96.0)$ & $5,767(93.8)$ & $3,575(86.2)$ & $17,735(88.3)$ & & \\
\hline Total OTUs & 210 & 44 & 87 & 139 & 344 & & \\
\hline
\end{tabular}

Firmicutes [35]. This implied that three of the impalas (1, 4, and 5), with Bacteroidetes as the most prevalent phylum, may have consumed a high starch diet, whereas impalas 2 and 3 may have consumed a high fiber diet. In contrast, dairy cattle fed a high grain (i.e., starch) diet had a higher frequency of Firmicutes than Bacteroidetes [36]. Because of these contrasting findings, we theorize that a combination of factors including, diet, season, geographical location, and the individual animal contributed to the dominance of Bacteroidetes or Firmicutes. Further classification of the phyla Bacteroidetes and Firmicutes to genus level identified the genera, Prevotella and Butyrivibrio, respectively. Because proteolytic bacteria belonging to the genus Prevotella was observed at higher frequencies in Impala 1, 4, and 5 it is hypothesized that these animals likely consumed a diet with increased protein content in comparison to Impalas 2 and 3, who had a diet higher in Butyrivibrio, which can biohydrogenate fatty acids and breakdown fiber and protein.

Although Bacteroidetes and Firmicutes are typically observed as the top two phyla within the rumen of domestic animals, Proteobacteria was the second most dominant phylum in the impala. Proteobacteria species at this frequency was previously observed by using a Phylochip microarray in Vermont moose [11] but at lower frequencies based upon nextgeneration sequencing on moose samples from Alaska, Norway, and Vermont amplified with the same primer pair (i.e., $27 \mathrm{~F}, 519 \mathrm{R})$ [31]. Furthermore, bacteria belonging to the phylum Proteobacteria were at frequencies less than $10 \%$ in feral dromedary camels in Australia, Moxotó goats from Brazil, elk, white-tailed deer from Canada, mithun in India, and dry dairy cattle in Canada [13, 29, 36-38]. Seeing that three impala had higher frequencies of Proteobacteria while two had frequencies that were in agreement with previous studies suggests an individual animal effect. Most notably, bacteria belonging to the genus Cupriavidus were the most common members from the phylum Proteobacteria. Bacteria belonging to the genus Cupriavidus are mesophilic, motile, Gram-negative, and typically found in soil. Although their optimum $\mathrm{pH}$ is between 7.0 and 8.0 and optimum temperature is $27^{\circ} \mathrm{C}$, they can grow between a pH 5.5 and 9.0 and a temperature of $37^{\circ} \mathrm{C}[39]$.

Previous research involving 24 male impala during the winter dry season showed that the average ruminal $\mathrm{pH}$ was $5.74 \pm 0.32$, and the average rumen temperature was between $30{ }^{\circ} \mathrm{C}$ and $41{ }^{\circ} \mathrm{C}$, suggesting that the impala rumen may provide a good environment for the growth of Cupriavidus [40]. The frequency of this genus is speculated to be due to the low grazing on grass, instead of browsing, and is linked to soil consumption during the dry season. Because bacteria belonging to the genus Cupriavidus were observed in all five impala samples and were most prevalent in Impala 2, it is speculated that, during the dry season, this genus may represent one of the core groups of bacteria within the present study. The abundance of Cupriavidus-related sequences in Impalas 1, 2, and 5 at the OTU level may also demonstrate that bacteria belonging to this genus play a role in the rumen metabolism of these individual animals. More studies should be performed on female impalas from the same region and from both male and female impalas during the summer to see if there are differences in seasonal dietary changes.

Impala Rumen Methanogens in Relation to Domestic and Wild Ruminants

In the present study, Methanobrevibacter species were the most dominant methanogens from the four impalas, similar to previous studies on a range of host species including Mediterranean water buffalo on three different diets in Brazil, sheep from Venezuela, sheep from Western Australia on three different diets, lambs on different high-grain diets in France, lactating Jersey and Holstein cows in Vermont, alpaca from Vermont, and in the Hoatzin from South America [24, 26, 41-45]. 
However, at the species level, the majority of the $16 \mathrm{~S}$ rRNA gene sequence reads from the highest represented OTU had the highest sequence identity to $M$. thaueri, a methanogen first isolated from cow feces and a member of the Methanobrevibacter smithii-gottschalkii-millerae-thaueri (SGMT) clade that uses hydrogen and carbon dioxide to produce methane [24, 46]. Although Impalas 1, 4, and 5 had OTU 1 with sequence identity to $M$. thaueri as the most abundant, Impala 3 had OTU 2 with sequence identity to M. smithii as its most abundant methanogen OTU. M. smithii was first isolated from human feces, and like $M$. thaneri, it also uses hydrogen and carbon dioxide to create methane. Unfortunately, we do not know the exact ages of the animals or the individual dry season diets that may have influenced different microbiome profiles for each animal. Nonetheless, the percentage of sequence reads in Impala 3 with specieslevel identity to $M$. thaueri was still higher than previously observed in other hosts, and it had the highest frequency of the proteolytic bacterial genus, Prevotella and lowest frequency of the genus Cupriavidus [7, 24, 43]. To date, no links between M. thaueri, Prevotella, and Cupriavidus have been demonstrated. Therefore, future research efforts should explore these relationships. In contrast to Impala 3, OTU 1 in Impala 4 represented $73 \%$ of its total sequence reads indicating that Impala 4 has some ruminal or individual component that causes $M$. thaueri-like species to thrive.

In previous studies exploring the ruminal methanogen populations, the percentage of sequences with similarity to M. thaueri was substantially lower in comparison to what was observed in all four impala. A low prevalence of M. thaueri-like methanogens was observed in sheep from Western Australia, fed oaten hay (6.2\%) or while grazing $(6.4 \%)$, in Norwegian reindeer on summer pasture, in cornfed feedlot cattle from Ontario, Canada (1.6\%), and in lactating Holsteins (0.6 \%) from Vermont, USA [7, 9, 24, 43]. However, the rumen methanogens present in sheep from Venezuela had $19.2 \%$ of all clones with $99 \%$ similarity to M. thaueri and had $39.4 \%$ (41/104) of clones with 97.9$98.5 \%$ identity to Methanobrevibacter gottschalkii [42]. The absence of $M$. thaueri-related sequences was observed in alpacas from Vermont, water buffalo on three different diets, sheep in Western Australia, sheep from Queensland, Australia, and in Sika deer from China [26, 34, 41, 43, 47]. Comparing the methanogen diversities of previous studies to the present study suggests that both the diet of the impala and the unknown factors in the rumen allow for M. thaueri-like methanogens to thrive over other methanogen species.

Although Methanobrevibacter was the dominant genus, the remaining $4.2 \%$ phylotypes belonged to the genus Methanosphaera a methanol-reducing and acetate-utilizing methanogen. Methanosphaera was previously found in less than $2 \%$ of the total clones in both Jersey and Holstein dairy cattle, in sheep from Western Australia, in Norwegian and Svalbard reindeer, and in alpacas [9, 10, 24, 26, 43]. Although Methanosphaera stadtmanae-like species were low in the impalas and in other ruminant species, it was the predominant methanogen observed in the feces of orangutans eating a diet rich in fruits [48]. These data suggest that, similar to other ruminants, the impala does not consume a diet high in pectin that is then degraded into methanol and acetate. Instead, the impala consumes a variable diet with extreme seasonal fluctuations that consist of periods of drought and rain. In contrast to a summer diet, the winter diet examined was proposed to be nutrient-poor [40]. Two previous studies involving the Svalbard and Norwegian reindeer suggested that seasonal fluctuations might change the appetite and microbial structures of the reindeer. Moreover, a nutrient-poor diet was observed in the Svalbard reindeer that resulted in the majority of the sequences being closely related to uncultured and uncharacterized methanogens now belonging to the newly proposed order Methanoplasmatales while Norwegian reindeer on a summer, nutrient-rich diet had clones with identities to Methanobrevibacter $[9,10]$. This statement may hold true for reindeer living in the Arctic, but further examination of the rumen microbiome of the impala and other ruminants living in a contrasting environment to the Arctic should be pursued to determine whether or not seasonal diet fluctuations are a factor in rumen methanogen populations.

Given the abundance of $M$. thaueri- and M. smithii-like sequence reads in all samples, it is likely that the diet of the impala and the dry season environment influenced the growth of these methanogens over other methanogens. More in depth descriptions of the methanogen species along with identifying the adult, female impala, prokaryotic community, and individual ages are needed to further clarify these abundances and compare with current male impala methanogen populations.

\section{Conclusion}

In the present study, we explored the bacterial and archaeal community structures of the impala rumen and found an abundance of bacteria belonging to the genus Cupriavidus and the methanogen $M$. thaueri. The latter was not previously seen in such high frequencies in previous studies. The presence of these two genera demonstrates that the rumen microbial diversity of the impala appears to be different than domesticated and other wild ruminants. However, the presence of the typical rumen phyla, Bacteroidetes, Proteobacteria, and Firmicutes, indicates a shared core rumen microbiome among ruminants, both wild and domesticated. Both the classified and dominant unclassified Bacteria are likely due to the winter dry season diet, gender, and individual impala.

Acknowledgments We thank Suzanne Ishaq and Rachel Smith for their assistance in the laboratory. 


\section{References}

1. Lundrigan B, Sproull K (2000) Aepyceros melampus. In: Anim. Divers. Web. http://animaldiversity.ummz.umich.edu/accounts/ Aepyceros_melampus/. Accessed 5 Apr 2013

2. Vrba ES, Schaller GB (2000) Antelopes, deer, and relatives. Yale University Press, New Haven

3. Schwab P, Debes PV, Witt T, Hartl GB, Hmwe SS, Zachos FE, Grobler JP (2012) Genetic structure of the common impala (Aepyceros melampus melampus) in South Africa: phylogeography and implications for conservation. J Zool Syst Evol Res 50:76-84

4. Hill RH (1982) Effect of dietary extremes on impala (Aepyceros melampus). Appl Environ Microbiol 44:198-202

5. Kingdon J (1997) The Kingdon field guide to African mammals. Academic Press, London

6. Skinner J, Smithers R (1990) The mammals of the Southern African subregion. University of Pretoria Press, Pretoria

7. Wright A-DG, Auckland CH, Lynn DH (2007) Molecular diversity of methanogens in feedlot cattle from Ontario and Prince Edward Island, Canada. Appl Environ Microbiol 73:4206-4210

8. Morgavi DP, Martin C, Jouany J-P, Ranilla MJ (2012) Rumen protozoa and methanogenesis: not a simple cause-effect relationship. Brit J Nutr 107:388-397

9. Sundset MA, Edwards JE, Cheng YF, Senosiain RS, Fraile MN, Northwood KS, Praesteng KE, Glad T, Mathiesen SD, Wright ADG (2009) Molecular diversity of the rumen microbiome of Norwegian reindeer on natural summer pasture. Microb Ecol 57: 335-348

10. Sundset MA, Edwards JE, Cheng YF, Senosiain RS, Fraile MN, Northwood KS, Praesteng KE, Glad T, Mathiesen SD, Wright ADG (2009) Rumen microbial diversity in Svalbard reindeer, with particular emphasis on methanogenic archaea. FEMS Microb Ecol 70:553-562

11. Ishaq SL, Wright A-D (2012) Insight into the bacterial gut microbiome of the North American moose (Alces alces). BMC Microbiol 12:1471-2180

12. Huang XD, Tan HY, Long R, Liang JB, Wright A-DG (2012) Comparison of methanogen diversity of yak (Bos grunniens) and cattle (Bos taurus) from the. BMC Microbiol 12:1-10

13. Gruninger RJ, Sensen CW, McAllister TA, Forster RJ (2014) Diversity of rumen bacteria in Canadian cervids. PLoS ONE 9:1-9

14. Yu Z, Morrison M (2004) Improved extraction of PCR-quality community DNA from digesta and fecal samples. Biotechniques 36:808-812

15. Denman S, McSweeney C (2006) Development of a real-time PCR assay for monitoring anaerobic fungal and cellulolytic bacterial populations within the rumen. FEMS Microb Ecol 58:572-582

16. Denman SE, Tomkins NW, McSweeney CS (2007) Quantitation and diversity analysis of ruminal methanogenic populations in response to the antimethanogenic compound bromochloromethane. FEMS Microb Ecol 62:313-322

17. Lane DJ (1991) 16S/23S rRNA sequencing. In: Nucleic acid techniques in bacterial systematics. New York, NY, pp 115-175

18. Turner S, Pryer K, Miao V, Palmer J (1999) Investigating deep phylogenetic relationships among cyanobacteria and plastids by small subunit rRNA sequence analysis. J Eukaryot Microbiol 46: 327-338

19. Schloss PD, Westcott SL, Rayabin T, Hall JR, Hartmann M, Hollister EB, Lesniewski RA, Oakley BB, Parks DH, Robinson CJ, Sahl JW, Stres B, Thallinger GG, Horn DJV, Weber CF (2009) Introducing MOTHUR: open-source, platform-independent, communitysupported software for describing and comparing microbial communities. Appl Environ Microbiol 75:7537-7541

20. Quince C, Lanzén A, Curtis TP, Davenport RJ, Hall N, Head IM, Read LF, Sloan WT (2009) Accurate determination of microbial diversity from 454 pyrosequencing data. Nat Methods 6:639-641
21. Altschul SF, Gish W, Miller W, Myers EW, Lipman DJ (1990) Basic local alignment search tool. J Mol Biol 215:403-410

22. Shannon C, Weaver W (1949) The mathematical theory of communication. University of Illinois Press, Urbana

23. Good I (1953) On population frequencies of species and the estimation of population parameters. Biometrika 40:237-264

24. King EE, Smith RP, St-Pierre B, Wright A-DG (2011) Differences in the rumen methanogen populations of lactating Jersey and Holstein dairy cows under the same diet regimen. Appl Environ Microbiol 77: $5682-5687$

25. Danielsson R, Schnürer A, Arthurson V, Bertilsson J (2012) Methanogenic population and $\mathrm{CH}_{4}$ production in Swedish dairy cows fed different levels of forage. Appl Environ Microbiol 78: 6172-6179

26. St-Pierre B, Wright A-DG (2012) Molecular analysis of methanogenic archaea in the forestomach of the alpaca (Vicugna pacos). BMC Microbiol 12:1-12

27. Singh KM, Tripathi AK, Pandya PR, Parnerkar S, Kothari RK, Joshi CG (2013) Molecular genetic diversity and quantitation of methanogen in ruminal fluid of buffalo (Bubalus bubalis) fed ration (wheat straw and concentrate mixture diet). Genet Res Int 2013:1-7

28. An D, Dong X, Dong Z (2005) Prokaryote diversity in the rumen of yak (Bos grunniens) and Jinnan cattle (Bos taurus) estimated by $16 \mathrm{~S}$ rDNA homology analyses. Anaerobe 11:207-215

29. Cunha IS, Barreto CC, Costa OYA, Bomfim MA, Castro AP, Kruger RH, Quirino BF (2011) Bacteria and archaea community structure in the rumen microbiome of goats (Capra hircus) from the semiarid region of Brazil. Anaerobe 17:118-124

30. Pitta DW, Kumar S, Veiccharelli B, Parmar N, Reddy B, Joshi CG (2014) Bacterial diversity associated with feeding dry forage at different dietary concentrations in the rumen contents of Mehshana buffalo (Bubalus bubalis) using 16S pyrotags. Anaerobe 25:31-41

31. Ishaq SL, Wright A-DG (2014) High-throughput DNA sequencing of the ruminal bacteria from moose (Alces alces) in Vermont, Alaska, and Norway. Microb Ecol 1-11

32. Kos M, Hoetmer AJ, Pretorius Y, Boer WF, Knegt H, Grant CC, Kohi E, Page B, Peel M, Slotow R, Waal C, Wieren SE, Prins HHT, Langevelde F (2011) Seasonal diet changes in elephant and impala in mopane woodland. Eur J Wildl Res 58:279-287

33. Kim M, Morrison M, Yu Z (2011) Status of the phylogenetic diversity census of ruminal microbiomes. FEMS Microb Ecol 76:49-63

34. Li ZP, Liu HL, Li GY, Bao K, Wang KY, Xu C, Yang YF, Yang FH, Wright A-DG (2013) Molecular diversity of rumen bacterial communities from tannin-rich and fiber-rich forage fed domestic Sika deer (Cervus nippon) in China. BMC Microbiol 13:1-12

35. Fernando S, Purvis H, Najar F, Sukharnikov L, Krehbiel C, Nagaraja T, Roe B (2010) Rumen microbial population dynamics during adaptation to a high-grain diet. Appl Environ Microbiol 76:74827490

36. Hook S, Steele M, Northwood K (2011) Impact of subacute ruminal acidosis (SARA) adaptation and recovery on the density and diversity of bacteria in the rumen of dairy cows. FEMS Microb Ecol 275-284

37. Das KC, Paul SS, Sahoo L, Baruah KK, Subudhi PK, Ltu KRC (2014) Bacterial diversity in the rumen of mithun (Bos frontalis) fed on mixed tree leaves and rice straw based diet. Afr J Microbiol Res 8: 1426-1433

38. Samsudin AA, Evans PN, Wright A-DG, Al Jassim R (2011) Molecular diversity of the foregut bacteria community in the dromedary camel (Camelus dromedarius). Env Microbiol 13:3024-3035

39. Makkar NS, Casipa LE (1987) Cupriavidus necator gen. nov., sp. nov. A nonobligate bacterial predator of bacteria in soil. Int J Syst Bacteriol 37:323-326

40. Booyse D, Dehority BA (2011) Protozoa and digestive tract parameters of the impala. Onderstepoort J Vet Res 78:1-5

41. Franzolin R, St-Pierre B, Northwood K, Wright A-DG (2012) Analysis of rumen methanogen diversity in water buffaloes 
(Bubalus bubalis) under three different diets. Microb Ecol 64:131139

42. Wright A-DG, Ma X, Obispo NE (2008) Methanobrevibacter phylotypes are the dominant methanogens in sheep from Venezuela. Microb Ecol 56:390-394

43. Wright A-DG, Williams AJ, Winder B, Christophersen CT, Rodgers SL, Smith KD (2004) Molecular diversity of rumen methanogens from sheep in Western Australia. Appl Environ Microbiol 70:1263-1270

44. Wright A-DG, Northwood KS, Obispo NE (2009) Rumen-like methanogens identified from the crop of the folivorous South American bird, the hoatzin (Opisthocomus hoazin). ISME J 3: $1120-1126$

45. Popova M, Morgavi DP, Martin C (2013) Methanogens and methanogenesis in the rumens and ceca of lambs fed two different high-grain-content diets. Appl Environ Microbiol 79: $1777-1786$

46. Miller TL, Lin C (2002) Description of Methanobrevibacter gottschalkii sp. nov., Methanobrevibacter thaueri sp. nov., Methanobrevibacter woesei, Methanobrevibacter wolinii. Int J Sys Evol Microbiol 52:819-822

47. Williams YJ, Popovski S, Rea SM, Skillman LC, Toovey AF, Northwood KS, Wright A-DG (2009) A vaccine against rumen methanogens can alter the composition of archaeal populations. Appl Environ Microbiol 75:1860-1866

48. Facey HV, Northwood KS, Wright A-DG (2012) Molecular diversity of methanogens in fecal samples from captive Sumatran orangutans (Pongo abelii). Am J Primat 74:408413 